\title{
Embryonic viability, lipase deficiency, hypertriglyceridemia and neonatal lethality in a novel LMF1-deficient mouse model
}

\author{
Nicole Ehrhardt ${ }^{1}$, Candy Bedoya ${ }^{2}$ and Miklós Péterfy ${ }^{1,2,3^{*}}$
}

\begin{abstract}
Background: Lipase Maturation Factor 1 (LMF1) is an ER-chaperone involved in the post-translational maturation and catalytic activation of vascular lipases including lipoprotein lipase (LPL), hepatic lipase $(H L)$ and endothelial lipase (EL). Mutations in LMF1 are associated with lipase deficiency and severe hypertriglyceridemia indicating the critical role of LMF1 in plasma lipid homeostasis. The currently available mouse model of LMF1 deficiency is based on a naturally occurring truncating mutation, combined lipase deficiency $(c / d)$, which may represent a hypomorphic allele. Thus, development of LMF1-null mice is needed to explore the phenotypic consequences of complete LMF1 deficiency.

Findings: In situ hybridization and APCR analysis in the normal mouse embryo revealed ubiquitous and high-level LMF1 expression. To investigate if LMF1 was required for embryonic viability, a novel mouse model based on a nullallele of LMF1 was generated and characterized. LMF1-/- progeny were born at Mendelian ratios and exhibited combined lipase deficiency, hypertriglyceridemia and neonatal lethality.

Conclusion: Our results raise the possibility of a previously unrecognized role for LMF1 in embryonic development, but indicate that LMF1 is dispensable for the viability of mouse embryo. The novel mouse model developed in this study will be useful to investigate the full phenotypic spectrum of LMF1 deficiency.
\end{abstract}

Keywords: Lipase Maturation Factor 1, LMF1, Lipase deficiency, Hyper-triglyceridemia

\section{Findings \\ Introduction}

Lipoprotein lipase (LPL), hepatic lipase (HL) and endothelial lipase (EL) are extracellular lipases involved in plasma lipid homeostasis [1]. The secretion and activity of these lipases depends on their post-translational maturation within the endoplasmic reticulum (ER) of lipaseexpressing cells [2]. The maturation of lipases involves folding and assembly of nascent polypeptides into catalytically active homodimers, a hallmark structural feature shared among LPL, HL and EL [3]. We have previously demonstrated that lipase maturation factor 1 (LMF1), an ER membrane protein, plays a critical role in lipase maturation $[4,5]$. In the absence of LMF1, lipases fail

\footnotetext{
*Correspondence: mpeterfy@ucla.edu

${ }^{1}$ Medical Genetics Research Institute, Cedars-Sinai Medical Center, Los Angeles, CA 90048, USA

${ }^{2}$ Department of Biomedical Sciences, Cedars-Sinai Medical Center, Los Angeles, CA 90048, USA

Full list of author information is available at the end of the article
}

to mature into active enzymes, are retained within the ER and undergo intracellular degradation [3]. Highlighting the critical role of LMF1 in lipase expression and lipid metabolism, patients with homozygous LMF1 mutations exhibit plasma lipase deficiency and hypertriglyceridemia [5-7].

LMF1 was initially identified as the gene disrupted by 'combined lipase deficiency' (cld), a naturally occurring mutation in the mouse [5]. Homozygous cld mutant mice exhibit deficiency in plasma LPL and HL activity, develop hyperchylomicronemia and die within a few days after birth likely due to circulatory problems [8]. While the $c l d$ mouse model has proven valuable for the identification of LMF1, it has several limitations. First, owing to the presence of a recessive lethal mutation ( $\mathrm{T}$, brachyury) in trans to the cld allele, "wild-type" $(+/+)$ progeny obtained from $c l d /+$ breeders are not viable, which precludes the use of $+/+$ littermate controls in phenotypic analysis [9]. Second, the cld mutation arose on an outbred genetic background harboring a variant form of chromosome 17, 
known as the $t$-haplotype, which is enriched in deleterious mutations affecting several nearby genes [9]. Consequently, phenotypes observed in cld mice cannot be unequivocally ascribed to LMF1 deficiency. Finally, the cld allele produces a truncated form of LMF1 (LMF1 ${ }^{\text {cld }}$ ) corresponding to $\sim 60 \%$ of the full-length protein. As LMF1 ${ }^{\text {cld }}$ is stable and correctly localizes to the ER membrane, cld may represent a hypomorphic allele [4]. In conclusion, characterization of the full phenotypic spectrum of LMF1deficiency requires the generation of mice with a nullallele of LMF1 on an inbred genetic background.

The present study was triggered by the unexpected observation of widespread LMF1 expression in the developing mouse embryo. This observation raised the possibility that LMF1 may be required for embryonic viability, which may not be apparent in the hypomorphic cld model. To test this hypothesis, we generated and characterized a novel mouse model of complete LMF1 deficiency. Our results demonstrate that whereas LMF1 is dispensable for the viability of mouse embryo, LMF1 deficiency is associated with lipase deficiency, hypertriglyceridemia and neonatal lethality. The mouse model developed in this study will facilitate the further characterization of LMF1 in development and metabolic regulation.

\section{Methods}

\section{Animals}

LMF1-deficient mice were generated from a gene-trapped 129/SvEvBrd Omnibank ES cell clone (OST195742) at the Texas A\&M Institute for Genomic Medicine [10]. The trapped allele (referred to as 'LMF1-' from here on) was transferred to the C57BL/6J background by backcrossing
(N4). Primers used for genotyping (wild-type allele: TG0048-5' and TG0048-3'; gene-trap allele: LTR2 and KO-A) are listed in Table 1 . Mice were maintained on standard laboratory chow (LabDiet 5001) in a specific pathogen-free facility under 14:10 hour light cycle. All animal studies were approved by the Institutional Animal Care and Use Committee at Cedars-Sinai Medical Center.

\section{RNA analysis}

In situ hybridization was carried out by Phylogeny Inc. as described [11]. ${ }^{35} \mathrm{~S}$-UTP-labeled sense and anti-sense cRNA probes were generated by in vitro transcription (Ambion) from a T7 and T3 promoter-appended PCR product (primers T7-LMF1 and T3-LMF1 in Table 1) representing the 5'-terminal 889 bp of the LMF1 open reading frame. RNA and cDNA from adult tissues was prepared as described previously [12] and cDNA from embryonic tissues was obtained from OriGene (TissueScan, MDRT). Real-time PCR was performed using LMF1 (\#4351372, Life Technologies) and GAPDH (\#4352339E) TaqMan assays (Figure 1B), or SybrGreen assays using primers for LMF1 (p6 and p7 in Table 1) and 36B4. For semi-quantitative RT-PCR analysis of the gene-trapped LMF1 allele, primers (p1-p5 in Table 1) spanning multiple exons were used as shown in Figure 2A.

\section{Plasma assays}

To obtain post-heparin plasma from newborn mice, pups were injected intraperitoneally with 10 units of heparin followed by decapitation and blood collection 20 minutes later. Blood was centrifuged $(4,500 \times \mathrm{g}$ for 5 min) in heparinized separation tubes and plasma was

Table 1 Primer sequences

\begin{tabular}{|c|c|c|}
\hline Name & Sequence & Application \\
\hline TG0048-3' & AGGCTAAGACTCTITAGGCTCAGG & Genotyping \\
\hline TG0048-5' & GGCGAGACGATGCTAATTCTATTCC & Genotyping \\
\hline LTR2 & AAATGGCGTTACTTAAGCTAGCTTGC & Genotyping \\
\hline KO-A & CCGCTITCCTGAAGTGAAGGA & Genotyping \\
\hline T7-LMF1 & GCCAGTAATACGACTCACTATAGGGATGCGCCCAGACAGCCTAGTA & IVT \\
\hline T3-LMF1 & GCCAGAATTAACCCTCACTAAAGGGATCTGCAGCACTCCAT & IVT \\
\hline p1 & ATGCGCCCAGACAGCCTAGT & RT-PCR \\
\hline p2 & GAGAACCTGCGTGCAATCCAT & RT-PCR \\
\hline p3 & CCCAGAGGGCAGTCATGA & RT-PCR \\
\hline p4 & GGGCATCTCGTCCTITGT & RT-PCR \\
\hline p5 & GTGACCTGTGCAGGTAGT & RT-PCR \\
\hline p6 & CGTGGAGCTTCTTGTGCCT & $\mathrm{qPCR}$ \\
\hline p7 & GGATCTGCAGCACTCCAT & $\mathrm{qPCR}$ \\
\hline 36B4-f & CACTGGTCTAGGACCCGAGAAG & qPCR \\
\hline 36B4-r & GGTGCCTCTGGAGATTTCG & $\mathrm{qPCR}$ \\
\hline
\end{tabular}




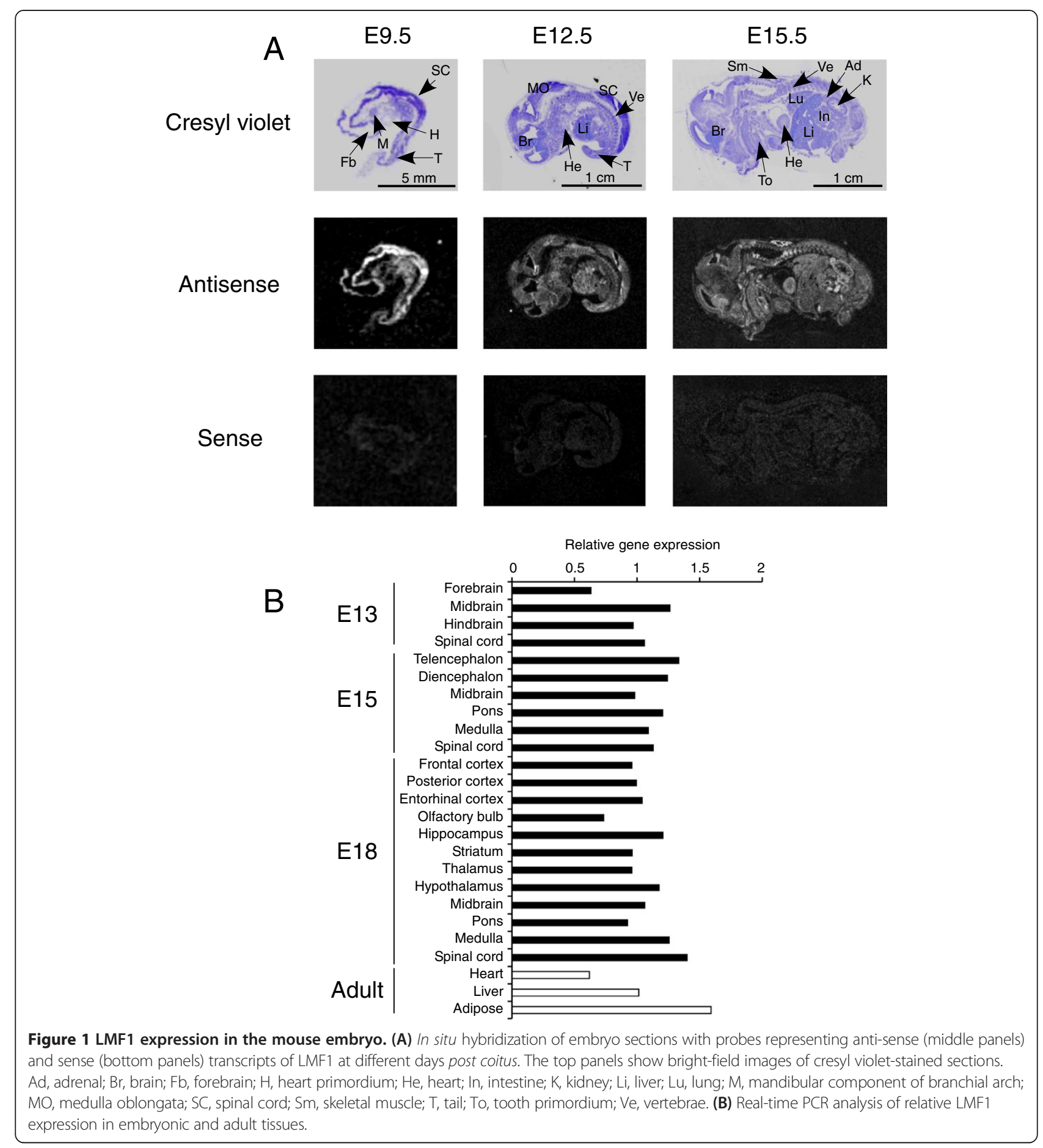

used to determine lipid levels, and enzymatic activities of LPL and HL as described [12]. For the assessment of plasma lipoprotein distribution, plasma obtained from 1-day-old pups was pooled and analyzed by FPLC at the Mouse Metabolic Phenotyping Center at Vanderbilt University School of Medicine. Because of high triglyceride content and viscosity, plasma samples from LMF1-/animals were diluted 30-fold before FPLC analysis. At this dilution, cholesterol concentrations in fractions could not be reliably determined.

\section{Data analysis}

Results are shown as means \pm S.E. Statistical analyses were performed with the SigmaStat software. Two-tailed unpaired Student's t-test was used to compare means, and chi-square test was applied for the analysis of genotype 


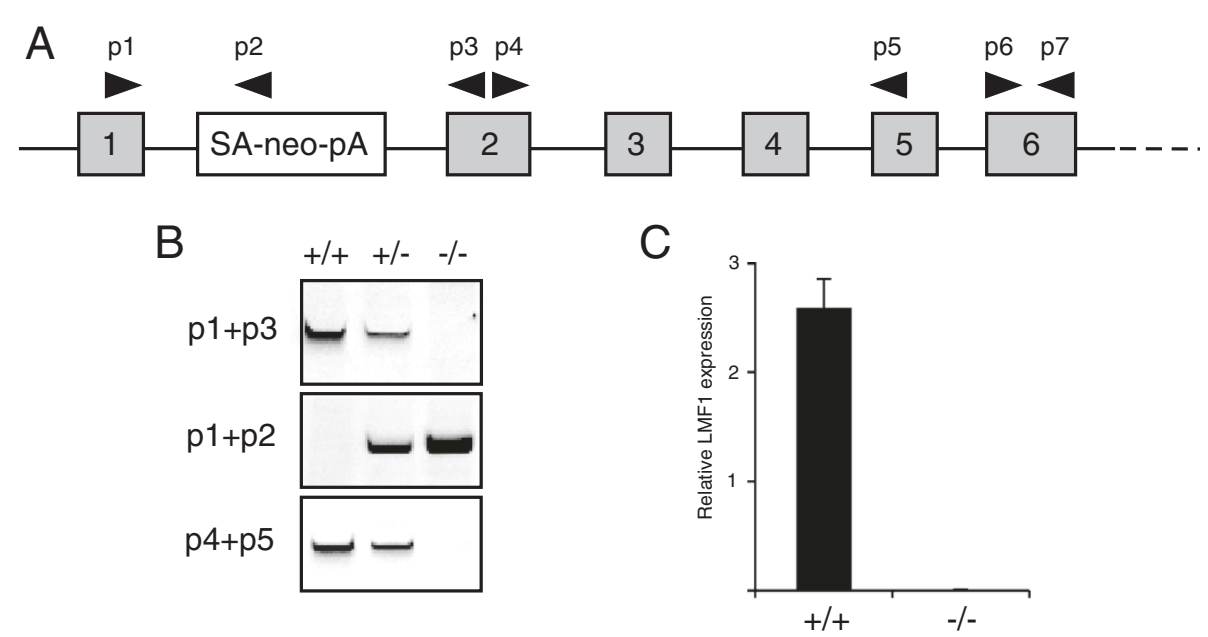

Figure 2 Generation of LMF1-/- mice. (A) Schematic illustration of the novel LMF1 allele showing a gene-trap insertion event in intron 1. Gray numbered boxes represent exons. The gene-trap cassette contains a splice acceptor sequence (SA), neomycin resistance gene (neo) and polyadenylation sequence (pA). Arrowheads indicate primers (p1-p5) used for RT-PCR analysis. (B) RT-PCR analysis of LMF1 expression in neonatal liver RNA. (C) qPCR analysis of LMF1 expression in mouse embryonic fibroblasts using primers p6 and p7 shown in panel A.

frequencies. A p-value $<0.05$ was considered statistically significant.

\section{Results}

\section{LMF1 expression in the developing mouse embryo}

Previous studies indicated that LMF1 was ubiquitously expressed in adult mouse tissues [5]. To investigate whether the broad expression pattern of LMF1 extends to embryonic tissues, we performed in situ hybridization studies in the mouse embryo at different stages of development (Figure 1A). In E9.5 mid-gestation embryos, strong LMF1 expression was detected in rudiments of the central nervous system, whereas lower mRNA levels were observed in other tissues. LMF1 exhibited ubiquitous expression pattern in E12.5 and E15.5 embryos with elevated levels in skeletal muscles, cartilage of vertebrae and intestine at late-gestation. To characterize LMF1 expression in the developing CNS further, we performed quantitative RT-PCR analysis on RNA isolated from distinct anatomical regions (Figure 1B). LMF1 showed uniform and ubiquitous expression in all regions and developmental stages tested. Furthermore, LMF1 mRNA levels were comparable to those in principal lipase-expressing adult tissues including adipose, heart and liver (Figure 1B).

\section{Generation of LMF1-deficient mice}

To explore the role of LMF1 in embryonic viability, we generated LMF1-deficient mice using an ES cell clone from a gene-trap library [10]. The targeted allele harbors a gene-trap cassette inserted within the first intron of the LMF1 gene and is predicted to produce a truncated transcript containing exon 1 (Figure 1A). Indeed, transcripts corresponding to exon 1 and the gene-trap cassette were readily detectable in mice carrying the mutant allele (Figure 1B, middle panel). Importantly, sequences 3' of exon 1 were undetectable in LMF1-/- mice (Figure 1B, top and bottom panels). Moreover, expression of exon 6 could not be detected in LMF1-/- mouse embryonic fibroblasts by qPCR, which confirms the absence of LMF1 transcripts with sequences downstream of the gene-trap integration site (Figure 1C). As exon 1 encodes the $\mathrm{N}$-terminal 64 residues of LMF1, which lacks membranespanning domains and corresponds to $\sim 10 \%$ of the fulllength polypeptide, we conclude that the gene-trap allele most likely represents a null-allele of LMF1.

\section{Characterization of LMF1-deficient mice}

To investigate the impact of LMF1 deficiency on embryonic viability, we genotyped offspring obtained from heterozygous LMF1+/- matings. On the first day after birth, the LMF1-/- genotype was represented at a Mendelian ratio (i.e. 25\%) among littermates indicating that LMF1 was dispensable for embryonic viability (Figure 3A). However, the proportion of LMF1-/- pups gradually decreased in subsequent days and no surviving LMF1deficient progeny could be identified 4 days after birth (Figure 3A).

To assess metabolic manifestations of LMF1 deficiency in the LMF1-/- model, we characterized newborn mice within the first day of life. LMF1-deficient neonates did not exhibit apparent morphological defects. However, their plasma had a milky appearance (Figure 3B), a consequence of $\sim 80$-fold elevated triglyceride concentration relative to unaffected littermates (Figure 3C). Hypertriglyceridemia in LMF1-/- pups was due to combined lipase deficiency as demonstrated by dramatically reduced 


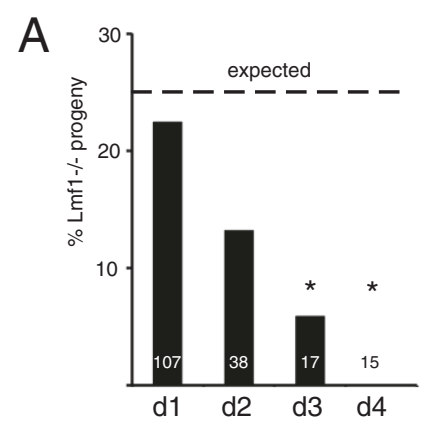

C
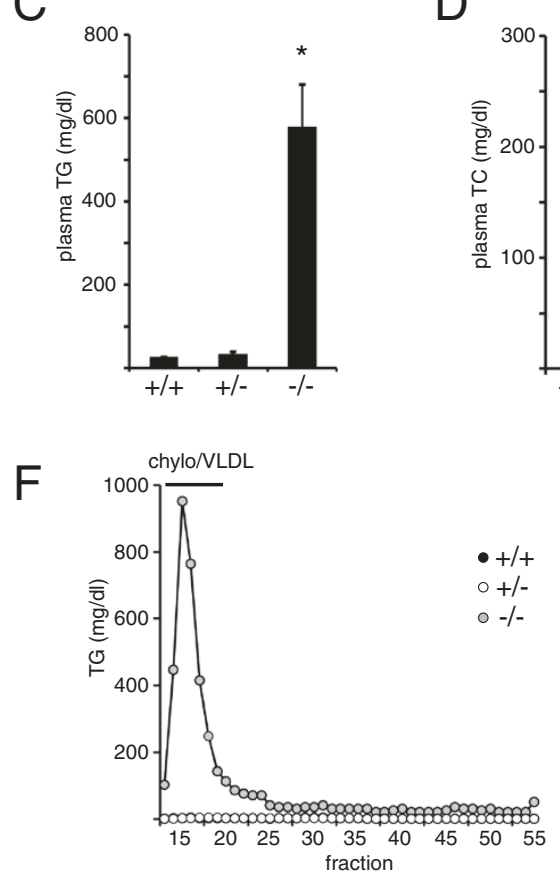

B

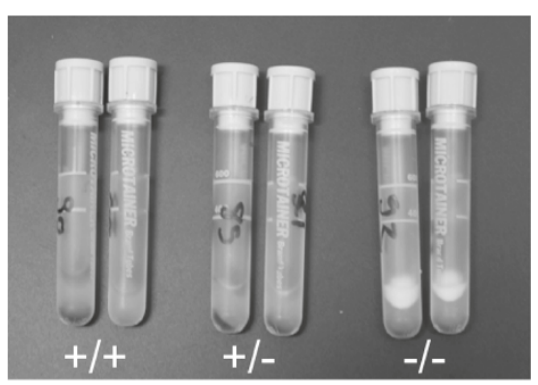

E

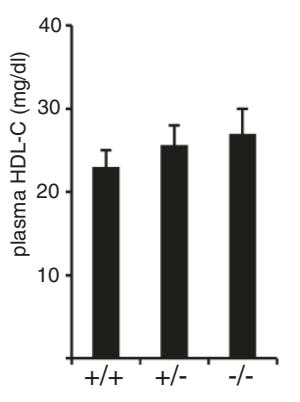

$\mathrm{H}$

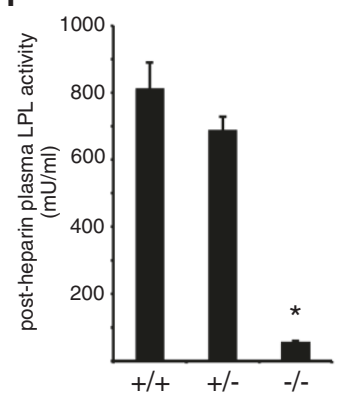

G

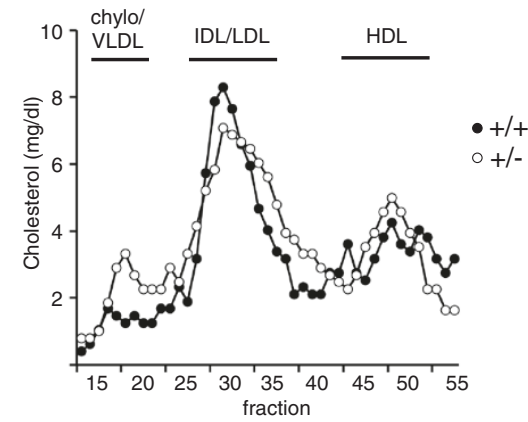

I

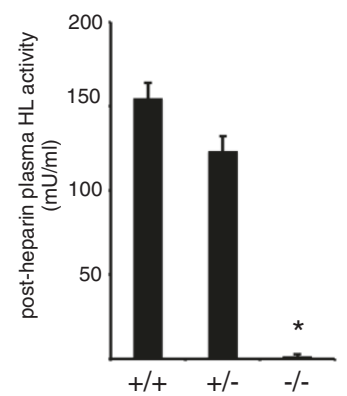

Figure 3 Characterization of LMF1-/- mice. (A) Survival of LMF1-deficient (LMF1-/-) progeny during days 1 to 4 (d1 to d4) after birth. Dashed line indicates Mendelian frequency (25\%) of $-/$ - genotype as expected from heterozygous matings. White numbers show total number of pups genotyped at each time-point. Asterisks indicate significant $(p<0.05)$ differences from expected genotype frequencies $\left(\chi^{2}\right.$ test). (B) White fat-cake indicates hyperlipidemia in plasma of -/- neonates. (C) Plasma triglyceride (TG), (D) total cholesterol (TC), and (E) HDL-cholesterol (HDL-C) levels are shown in newborn mice. (F) Plasma triglyceride and $\mathbf{( G )}$ cholesterol profiles were determined by FPLC analysis. (H) Post-heparin LPL and (I) $\mathrm{HL}$ activities in newborn mice. *, $\mathrm{p}<0.05$.

post-heparin LPL and HL activities (Figure $3 \mathrm{H}$ and I). As expected, triglycerides were overwhelmingly associated with the chylomicron/VLDL fraction in LMF1-/- plasma (Figure 3F). Relative to wild-type and heterozygous littermates, LMF1-/- mice also demonstrated elevated total cholesterol (Figure 3D), but similar HDL-cholesterol 
levels (Figure 3E). We were unable to directly assess the cholesterol profile in LMF1-/- mice, because severe lipemia and high viscosity necessitated dilutions of samples before FPLC analysis to an extent, which prevented the detection of cholesterol in fractions. Nonetheless, wild-type and heterozygous mice exhibited similar plasma cholesterol distribution (Figure 3G), where cholesterol was predominantly associated with IDL/LDL particles, a characteristic feature of fetal murine lipoprotein profile [13].

\section{Discussion}

In the present study, we generated a novel mouse model of LMF1 deficiency using gene-trap mutagenesis. The new model offers advantages over the naturally occurring cld mutant mouse strain used in previous studies $[5,8]$. First, in contrast to a truncating mutation in the cld model, the gene-trap insertion characterized here represents a definitive null-allele and allows analysis of the full phenotypic manifestation of LMF1 deficiency. An additional improvement of the new model over cld is that wild-type littermates are viable, which enables characterization of the potential phenotypic consequences of heterozygous LMF1 deficiency. Finally, the gene-trap allele is on an inbred genetic background devoid of the confounding genetic effects associated with the $c l d$ mutation [9].

We unexpectedly detected ubiquitous and relatively high-level LMF1 expression in the mouse embryo. This observation raised the possibility that in addition to its established role in postnatal lipid metabolism, LMF1 may also be an important factor in embryogenesis. While the role of vascular lipases during development remains poorly characterized, embryonic expression of all three LMF1-dependent lipases (i.e. LPL, HL and EL) has previously been documented $[14,15]$. To begin to address the potential role of LMF1 in development, we first asked whether LMF1 deficiency affects the viability of embryos. Our results demonstrate that despite widespread expression in the developing embryo, LMF1 is not required for embryonic survival. However, postnatal viability of LMF1-/- pups is severely compromised, as no surviving LMF1-deficient progeny was detected a few days after birth. Neonatal lethality has also been observed in cld mice [8] and is thought to be a consequence of circulatory problems associated with severe hyperchylomicronemia, which results from the inability to utilize dietary fat during suckling [16]. Indeed, LMF1-/- pups exhibit hypertriglyceridemia and severely diminished postheparin LPL and HL activities, hallmark features of LMF1 deficiency in the cld mouse model [8]. In addition to hypertriglyceridemia, plasma concentrations of total cholesterol are also elevated in LMF1-/- mice, a likely consequence of diminished catabolism and accumulation of chylomicron particles due to LPL deficiency [17]. In contrast to total cholesterol, HDL-cholesterol levels are unaffected in LMF1-/- plasma. At first glance, this is a surprising observation considering the critical role of LPL in the maturation of HDL particles [18] and severely reduced HDL-cholesterol in LPL-deficient mice $[17,19,20]$. However, in addition to LPL, LMF1-/- animals are also deficient in active HL and EL [7], lipases that promote HDL catabolism [21-23]. Thus, we propose that unaltered HDL-cholesterol level in LMF1-/- mice is a result of combined lipase deficiency involving lipases with opposite effects on HDL metabolism.

LMF1-deficient mice developed in this work will allow in-depth investigations of the role of LMF1 in development. However, early lethality is a limitation of this model for metabolic studies in the adult organism. Neonatal lethality in LMF1-/- mice is not unique among mouse models of hypertriglyceridemia. LPL-deficient mice die within a few days after birth, most likely as a consequence of restricted oxygen exchange in lipid-engorged lung capillaries [17]. In contrast, hypertriglyceridemia in mice deficient in GPIHBP1, a protein involved in the trans-endothelial transport of LPL, is not associated with increased mortality owing to the availability of a functional pool of LPL in the neonatal liver $[24,25]$. Two strategies have been used to rescue LPL-deficient mice from neonatal lethality. First, transient expression of LPL through adenoviral gene transfer allowed a small fraction of infected LPL-/- progeny to reach adulthood and enabled metabolic characterization of LPL-deficiency $[18,20,26]$. We attempted a similar strategy to rescue LMF1-/- pups using adenovirus expressing LMF1, but have been unable to recover adult LMF1-deficient mice (unpublished observation). Importantly, LMF1-deficient mice are not only devoid of active LPL, but also HL and EL, which may result in more severe morbidity relative to LPL-deficiency only and explain why transient expression of LMF1 is insufficient for rescue. Consistent with this explanation, HL/ EL double knock-out mice suffer from neonatal lethality [23], which raises the possibility that combined HL/EL-deficiency contributes to mortality in LMF1-/- mice. A second strategy that has been successfully applied to rescue LPL-/ - mice is based on transgenic complementation of LPL expression in single tissues such as heart, skeletal muscle and liver [27-29]. A similar approach is currently pursued in our laboratory to rescue LMF1-/- mice using a muscle-specific LMF1 transgene [12].

In conclusion, we validated a new LMF1-deficient mouse model by demonstrating that it recapitulates salient phenotypes of $c l d$ mutant mice including neonatal lethality, dyslipidemia and combined lipase deficiency. At the same time, our study also confirms that phenotypes previously observed in the cld model are genuine consequences of LMF1 deficiency, as opposed to unrelated mutations 
present in the cld genetic background [9]. The fact that our initial characterization of LMF1-/- neonates did not reveal novel phenotypes beyond those already observed in cld mice is consistent with the possibility that cld represents a null-allele of LMF1. However, more detailed phenotypic characterization will be necessary before a definitive conclusion can be reached. The LMF1-deficient mouse model developed in this study will facilitate further analysis of LMF1 function in development and metabolic regulation.

\begin{abstract}
Abbreviations
cld: 'combined lipase deficiency' mutation; CNS: Central nervous system; EL: Endothelial lipase; ER: Endoplasmic reticulum; HDL: High-density lipoprotein; HL: Hepatic lipase; IVF: in vitro translation; LDL: Low-density lipoprotein; LMF1: Lipase maturation factor 1; LPL: Lipoprotein lipase; qPCR: quantitative PCR; RT-PCR: Reverse transcription polymerase chain reaction; VLDL: Very low-density lipoprotein.
\end{abstract}

\section{Competing interests}

The authors declare no conflict of interest.

\section{Authors' contributions}

NE carried out molecular genetic and in vivo experiments, participated in the design of the study and performed statistical analysis. CB carried out analyses of embryonic LMF1 expression. MP conceived the study, and participated in its design and coordination and drafted the manuscript. All authors read and approved the final manuscript.

\section{Acknowledgements}

The authors gratefully acknowledge Hui Mao and Jessica Latter for technical assistance. This study was funded by the National Institutes of Health (HL-028481 and UL1TR000124) and the Cedars-Sinai Medical Center. Vanderbilt University School of Medicine MMPC is supported by U24 DK059637.

\section{Author details}

${ }^{1}$ Medical Genetics Research Institute, Cedars-Sinai Medical Center, Los Angeles, CA 90048, USA. ²Department of Biomedical Sciences, Cedars-Sinai Medical Center, Los Angeles, CA 90048, USA. ${ }^{3}$ Department of Medicine, David Geffen School of Medicine, University of California, Los Angeles, CA 90095, USA.

\section{Received: 16 April 2014 Accepted: 12 August 2014}

Published: 16 August 2014

\section{References}

1. Hasham SN, Pillarisetti S: Vascular lipases, inflammation and atherosclerosis. Clin Chim Acta 2006, 372:179-183.

2. Doolittle MH, Peterfy M: Mechanisms of lipase maturation. Clin Lipido/ 2010, 5:71-85.

3. Doolittle $\mathrm{MH}$, Ehrhardt $\mathrm{N}$, Peterfy M: Lipase maturation factor 1: structure and role in lipase folding and assembly. Curr Opin Lipidol 2010, 21:198-203.

4. Doolittle MH, Neher SB, Ben-Zeev O, Ling-Liao J, Gallagher CM, Hosseini M, Yin F, Wong $H$, Walter $P$, Peterfy M: Lipase maturation factor LMF1, membrane topology and interaction with lipase proteins in the endoplasmic reticulum. J Biol Chem 2009, 284:33623-33633.

5. Peterfy M, Ben-Zeev $\mathrm{O}$, Mao HZ, Weissglas-Volkov D, Aouizerat BE, Pullinger CR, Frost PH, Kane JP, Malloy MJ, Reue K, Pajukanta P, Doolittle MH: Mutations in LMF1 cause combined lipase deficiency and severe hypertriglyceridemia. Nat Genet 2007, 39:1483-1487.

6. Cefalu AB, Noto D, Arpi ML, Yin F, Spina R, Hilden H, Barbagallo CM, Carroccio A, Tarugi P, Squatrito S, Vigneri R, Taskinen MR, Peterfy M, Averna MR: Novel LMF1 nonsense mutation in a patient with severe hypertriglyceridemia. J Clin Endocrinol Metab 2009, 94:4584-4590.

7. Ben-Zeev O, Hosseini M, Lai CM, Ehrhardt N, Wong H, Cefalu AB, Noto D, Averna MR, Doolittle MH, Peterfy M: Lipase maturation factor 1 is required for endothelial lipase activity. J Lipid Res 2011, 52:1162-1169.
8. Paterniti JR Jr, Brown WV, Ginsberg HN, Artzt K: Combined lipase deficiency (cld): a lethal mutation on chromosome 17 of the mouse. Science 1983, 221:167-169.

9. Peterfy M, Mao HZ, Doolittle MH: The cld mutation: narrowing the critical chromosomal region and selecting candidate genes. Mamm Genome 2006, 17:1013-1024.

10. Zambrowicz BP, Abuin A, Ramirez-Solis R, Richter LJ, Piggott J, BeltrandelRio H, Buxton EC, Edwards J, Finch RA, Friddle CJ, Gupta A, Hansen G, Hu Y, Huang W, Jaing C, Key BW Jr, Kipp P, Kohlhauff B, Ma ZQ, Markesich D, Payne R, Potter DG, Qian N, Shaw J, Schrick J, Shi ZZ, Sparks MJ, Van Sligtenhorst I, Vogel P, Walke W, et al: Wnk1 kinase deficiency lowers blood pressure in mice: a gene-trap screen to identify potential targets for therapeutic intervention. Proc Natl Acad Sci U S A 2003, 100:14109-14114.

11. Hu MC, Wang YP, Mikhail A, Qiu WR, Tan TH: Murine p38-delta mitogen-activated protein kinase, a developmentally regulated protein kinase that is activated by stress and proinflammatory cytokines. $J$ Biol Chem 1999, 274:7095-7102.

12. Hosseini M, Ehrhardt N, Weissglas-Volkov D, Lai CM, Mao HZ, Liao JL, Nikkola E, Bensadoun A, Taskinen MR, Doolittle MH, Pajukanta P, Peterfy M: Transgenic expression and genetic variation of Lmf1 affect LPL activity in mice and humans. Arterioscler Thromb Vasc Biol 2012, 32:1204-1210.

13. van Straten EM, Huijkman NC, Baller JF, Kuipers F, Plosch T: Pharmacological activation of $L X R$ in utero directly influences $A B C$ transporter expression and function in mice but does not affect adult cholesterol metabolism. Am J Physiol Endocrinol Metab 2008, 295:E1341-E1348.

14. Semenkovich CF, Chen SH, Wims M, Luo CC, Li WH, Chan L: Lipoprotein lipase and hepatic lipase mRNA tissue specific expression, developmental regulation, and evolution. J Lipid Res 1989, 30:423-431.

15. Lindegaard ML, Nielsen JE, Hannibal J, Nielsen LB: Expression of the endothelial lipase gene in murine embryos and reproductive organs. J Lipid Res 2005, 46:439-444.

16. Reue $\mathrm{K}$, Doolittle MH: Naturally occurring mutations in mice affecting lipid transport and metabolism. J Lipid Res 1996, 37:1387-1405.

17. Weinstock PH, Bisgaier CL, Aalto-Setala K, Radner H, Ramakrishnan R, Levak-Frank S, Essenburg AD, Zechner R, Breslow JL: Severe hypertriglyceridemia, reduced high density lipoprotein, and neonatal death in lipoprotein lipase knockout mice. Mild hypertriglyceridemia with impaired very low density lipoprotein clearance in heterozygotes. J Clin Invest 1995, 96:2555-2568.

18. Strauss JG, Frank S, Kratky D, Hammerle G, Hrzenjak A, Knipping G, von Eckardstein A, Kostner GM, Zechner R: Adenovirus-mediated rescue of lipoprotein lipase-deficient mice. Lipolysis of triglyceride-rich lipoproteins is essential for high density lipoprotein maturation in mice. J Biol Chem 2001, 276:36083-36090.

19. Coleman T, Seip RL, Gimble JM, Lee D, Maeda N, Semenkovich CF: $\mathrm{COOH}$-terminal disruption of lipoprotein lipase in mice is lethal in homozygotes, but heterozygotes have elevated triglycerides and impaired enzyme activity. J Biol Chem 1995, 270:12518-12525.

20. Zhang X, Qi R, Xian X, Yang F, Blackstein M, Deng X, Fan J, Ross C, Karasinska J, Hayden MR, Liu G: Spontaneous atherosclerosis in aged lipoprotein lipase-deficient mice with severe hypertriglyceridemia on a normal chow diet. Circ Res 2008, 102:250-256.

21. Busch SJ, Barnhart RL, Martin GA, Fitzgerald MC, Yates MT, Mao SJ, Thomas $C E$, Jackson RL: Human hepatic triglyceride lipase expression reduces high density lipoprotein and aortic cholesterol in cholesterol-fed transgenic mice. J Biol Chem 1994, 269:16376-16382.

22. Ishida T, Choi S, Kundu RK, Hirata K, Rubin EM, Cooper AD, Quertermous T: Endothelial lipase is a major determinant of HDL level. J Clin Invest 2003, 111:347-355.

23. Brown RJ, Lagor WR, Sankaranaravanan S, Yasuda T, Quertermous T, Rothblat GH, Rader DJ: Impact of combined deficiency of hepatic lipase and endothelial lipase on the metabolism of both high-density lipoproteins and apolipoprotein B-containing lipoproteins. Circ Res 2010, 107:357-364.

24. BeigneuX AP, Davies BS, Gin P, Weinstein MM, Farber E, Qiao X, Peale F, Bunting S, Walzem RL, Wong JS, Blaner WS, Ding ZM, Melford K, Wongsiriroj N, Shu X, de Sauvage F, Ryan RO, Fong LG, Bensadoun A, Young SG: Glycosylphosphatidylinositol-anchored high-density lipoprotein-binding protein 1 plays a critical role in the lipolytic processing of chylomicrons. Cell Metab 2007, 5:279-291.

25. Weinstein MM, Tu Y, Beigneux AP, Davies BS, Gin P, Voss C, Walzem RL, Reue K, Tontonoz P, Bensadoun A, Fong LG, Young SG: Cholesterol intake 
modulates plasma triglyceride levels in glycosylphosphatidylinositol HDL-binding protein 1-deficient mice. Arterioscler Thromb Vasc Biol 2010, 30:2106-2113.

26. Ding YL, Wang YH, Huang W, Liu G, Ross C, Hayden MR, Yang JK: Glucose intolerance and decreased early insulin response in mice with severe hypertriglyceridemia. Exp Biol Med 2010, 235:40-46.

27. Levak-Frank S, Hofmann W, Weinstock PH, Radner H, Sattler W, Breslow JL, Zechner R: Induced mutant mouse lines that express lipoprotein lipase in cardiac muscle, but not in skeletal muscle and adipose tissue, have normal plasma triglyceride and high-density lipoprotein-cholesterol levels. Proc Natl Acad Sci U S A 1999, 96:3165-3170.

28. Levak-Frank S, Weinstock PH, Hayek T, Verdery R, Hofmann W, Ramakrishnan R, Sattler W, Breslow JL, Zechner R: Induced mutant mice expressing lipoprotein lipase exclusively in muscle have subnormal triglycerides yet reduced high density lipoprotein cholesterol levels in plasma. J Biol Chem 1997, 272:17182-17190.

29. Merkel M, Weinstock PH, Chajek-Shaul T, Radner H, Yin B, Breslow JL, Goldberg IJ: Lipoprotein lipase expression exclusively in liver. A mouse model for metabolism in the neonatal period and during cachexia. J Clin Invest 1998, 102:893-901.

doi:10.1186/1743-7075-11-37

Cite this article as: Ehrhardt et al:: Embryonic viability, lipase deficiency, hypertriglyceridemia and neonatal lethality in a novel LMF1-deficient mouse model. Nutrition \& Metabolism 2014 11:37.

\section{Submit your next manuscript to BioMed Central and take full advantage of:}

- Convenient online submission

- Thorough peer review

- No space constraints or color figure charges

- Immediate publication on acceptance

- Inclusion in PubMed, CAS, Scopus and Google Scholar

- Research which is freely available for redistribution 